-Full Paper-

\title{
Exogenous Adenosine Reduces the Mitochondrial Membrane Potential of Murine Oocytes During the Latter Half of In Vitro Maturation and Pronuclear Formation Following Chemical Activation
}

\author{
Wataru FUJII' ${ }^{1)}$ and Hiroaki FUNAHASHI' \\ 1) Department of Animal Science, Graduate School of Natural Science and Technology, Okayama University, Okayama \\ 700-8530, Japan
}

\begin{abstract}
The present study was undertaken to determine the effect of nucleosides on nuclear and cytoplasmic maturation of mouse oocytes. Oocyte-cumulus complexes (OCCs) were collected from large antral follicles $4 \mathrm{~h}$ after eCG-hCG treatment and cultured in maturation medium with or without nucleosides (4 ribo- and 4 deoxyribonucleosides) for $12 \mathrm{~h}$. A majority of the oocytes examined developed to the metaphase-II stage, and the same result was found with in-vivo matured oocytes. However, mitochondrial membrane potential (MMP) was significantly lower in the oocytes matured in the presence of nucleosides than in the nucleoside-free controls. Oocyte MMP increased in vivo between 8 to $12 \mathrm{~h}$ after hCG injection, whereas no increases in MMP were observed in oocytes matured in the presence of nucleosides. Oocyte MMP was significantly lower only when OCCs were exposed to nucleosides for the latter $8 \mathrm{~h}$ of IVM. When OCCs were exposed to adenosine during the latter $8 \mathrm{~h}$ of IVM, MMP was lower compared with in-vivo matured oocytes, whereas a mixture of other ribonucleosides (guanosine, cytidine and uridine) did not affect the level of MMP. The developmental competence of oocytes exposed to adenosine during the latter $8 \mathrm{~h}$ of IVM was lower after parthenogenetic activation due to the lower pronuclear formation of the oocytes. These observations indicate that adenosine inhibits increases in oocyte MMP during the latter half of meiotic maturation and detrimentally affects cytoplasmic maturation.
\end{abstract}

Key words: Adenosine, Mitochondrial membrane potential (MMP), Mouse, Oocyte

(J. Reprod. Dev. 55: 187-193, 2009)

n response to hormonal stimulation, mammalian oocytes generally resume meiosis from the germinal vesicle $(\mathrm{GV})$ stage and complete nuclear maturation by arresting again at the metaphase-II (MII) stage [1, 2]. During this process, hormonal signal transductions dexterously control the physiological and cytological changes in oocytes and the surrounding cumulus cells, including the dynamic distributional change in mitochondria, important organelles for oxidative glycolysis of exogenous energy substrates, glucose and pyruvate [3]. Mitochondrial activity produces cellular energy sources, ATP and NADPH, utilized in the cytological systems of oocytes and thus are well integrated with the developmental competence of oocytes [4]. These energy sources maintain a reduced intracellular glutathione level [5]. Therefore, the contents of these energy sources are useful indicators of cellular viability and quality [6]. Irregular mitochondrial function has been reported to affect oocyte maturation [7], and in several species, including mice $[8,9]$, active mitochondria are also known to relocate during oocyte maturation [3]. However, the environmental factors affecting and controlling the mitochondrial activity of oocytes are still not well known.

Nucleosides, including ribonucleosides (adenosine, guanosine, cytidine and uridine) and deoxyribonucleosides (deoxyadenosine, deoxyguanosine, deoxycytidine and thymidine), are commonly contained in intra- and extracellular fluids. Nucleosides are criti-

Accepted for publication: December 13, 2008

Published online in J-STAGE: February 6, 2009

Correspondence: H Funahashi (e-mail: hirofun@cc.okayama-u.ac.jp) cally important in many metabolic processes, serving as constituents of DNA, RNA, cofactors and second messengers. High uptake of ribonucleosides and alteration of metabolite distribution has been observed in both cumulus-enclosed and denuded GV oocytes [10]. Adenosine and hypoxanthine have been reported to be present in preparations of mouse ovarian follicular fluid [11], and a significant decrease in the concentrations of these purines has been observed 2 to $5 \mathrm{~h}$ after hCG stimulation in the follicular fluid of mice after GV breakdown (GVBD) [12]. Although adenosine alone has little inhibitory effect on GVBD at this time point, in the presence of both purines, mouse oocytes maintain meiotic arrest in vitro [11]. However, uridine taken up by cumulus cells is transferred to the oocyte [13] and appears to block adenosine uptake by oocyte cumulus complexes [14]. Guanosine appears to maintain meiotic arrest of cumulus-enclosed oocytes $[15,16]$. While the effect of nucleosides on the mitochondrial activity of mouse oocytes during meiosis is not yet well known, nucleosides may be associated with the mitochondrial activity of oocytes.

The present study was undertaken to examine the effect of nucleosides on the mitochondrial membrane potential (MMP) of mouse oocytes during meiotic maturation in vitro and developmental competence following chemical oocyte activation.

\section{Materials and Methods}

Chemicals and culture media

All chemical reagents were purchased from Sigma (Sigma-Ald- 
rich, St. Louis, MO, USA) unless stated otherwise.

$\mathrm{NaCl}, \mathrm{KCl}$ and $\mathrm{KH}_{2} \mathrm{PO}_{4}$ were purchased from Nacalai Tesque (Kyoto, Japan). $\mathrm{NaHCO}_{3}$ and $\mathrm{CaCl}_{2}$ were purchased from Ishizu Seiyaku (Osaka, Japan). Alpha-MEM with or without ribonucleosides (10 $\mu \mathrm{g} / \mathrm{ml}$ adenosine, $10 \mu \mathrm{g} / \mathrm{ml}$ guanosine, $10 \mu \mathrm{g} / \mathrm{ml}$ cytidine and $10 \mu \mathrm{g} / \mathrm{ml}$ uridine) and deoxyribonucleosides (10 $\mu \mathrm{g} / \mathrm{ml}$ 2'deoxyadenosine, 2'deoxyguanosine, thymidine and $11 \mu \mathrm{g} / \mathrm{ml}$ 2'deoxycytidine $\mathrm{HCl}$ ) were purchased from Gibco (Invitrogen, Carlsbad, CA, USA). Equine chorionic gonadotropin (eCG) and human chorionic gonadotropin (hCG) were purchased from Asuka Pharmaceutical (Tokyo, Japan).

M2 medium was used for collection of oocyte-cumulus complexes (OCCs) and some manipulation of oocytes. Alpha-MEM medium (with or without ribonucleosides and deoxyribonucleosides) supplemented with $0.23 \mathrm{mM}$ pyruvate, $75 \mu \mathrm{g} / \mathrm{ml}$ penicillin $\mathrm{G}, 50 \mu \mathrm{g} / \mathrm{ml}$ streptomycin sulfate and $3 \mathrm{mg} / \mathrm{ml}$ bovine serum albumin was used for in vitro maturation, which was performed as previously described $[17,18]$.

\section{Collection and culture of OCCs}

Oocyte collection and culture were carried out as previously described [19, 20]. Following the guidelines for animal experiments at Okayama University, three-to-five week-old female C57BL/6J mice were superovulated by intraperitoneal injection of $7.5 \mathrm{IU}$ hCG following $7.5 \mathrm{IU}$ eCG with an interval of $48 \mathrm{~h}$. The ovaries were removed from the mice $48 \mathrm{~h}$ after eCG injection or 4 $\mathrm{h}$ after hCG injection and then placed into M2 medium. Large antral follicles on the surface of the ovaries were punctured with 27-gauge needles to release OCCs. The OCCs were transferred into IVM medium, washed well and cultured in the same medium at $37 \mathrm{C}$ in $5 \%$ atmospheric $\mathrm{CO}_{2}$ in air for $12 \mathrm{~h}$. Oocytes matured in vivo were collected from the oviductal ampulla of mice $16 \mathrm{~h}$ after hCG injection.

\section{Measurement of MMP in ooplasm}

Oocyte MMP was measured according to the methods previously described [21, 22], with some modifications. Oocytes were denuded by gently pipetting in and out through a glass pipette following culture with $0.1 \%$ hyaluronidase in M2 medium for 5 min. The zonae pellucidae of the denuded oocytes were removed in an acidified Tyrode's solution ( $\mathrm{pH}=2.5$ ). The zona-free oocytes were transferred to M2 medium supplemented with $20 \mu \mathrm{g} / \mathrm{ml}$ 5,5',6,6'tetrachloro-1,1',3,3'-tetraethylbenzimidazolcarbocyanine iodide (JC-1) and incubated at $37 \mathrm{C}$ for $30 \mathrm{~min}$. The oocytes were then washed in M2 medium and observed using a confocal laser scanning microscopy (FV300; Olympus, Tokyo, Japan) configured to detect excitation wavelengths of $529 \mathrm{~nm}$ (green) and $590 \mathrm{~nm}$ (red). Images of the oocytes were captured, and the fluorescence intensity was quantified using the Image-J software (NIH). MMP was expressed as the ratio of red per green fluorescence intensity.

\section{Observation of nuclear maturation}

Oocytes were mounted, fixed in $10 \%$ formalin in phosphate buffered solution, dehydrated in 95\% ethanol and stained with 2.5\% lacmoid for $5 \mathrm{~min}$. Following washing with acetoglycerol, the meiotic stage of the oocytes was determined by phase contrast microscopy (Eclipse 80i; Nikon, Tokyo, Japan).

\section{Experimental design}

Experiment 1: To determine the effect of nucleosides (ribonucleosides plus deoxyribonucleosides) during the whole culture period for oocyte maturation on the nuclear maturation and MMP of oocytes, OCCs were collected from mice $48 \mathrm{~h}$ after eCG injection and $4 \mathrm{~h}$ after hCG injection and cultured in IVM medium with or without nucleosides for 16 and $12 \mathrm{~h}$, respectively. After culture, the meiotic stages of the oocytes were determined, the percentage of mature oocytes was compared with that of the in-vivo matured oocytes. The MMP of the oocytes with a first polar body was also determined.

Experiment 2: OCCs were collected $4 \mathrm{~h}$ after hCG injection, and then meiotic progression and the changes in MMP during culture in the presence of nucleosides were examined. The meiotic stages and MMPs of the oocytes were compared at 0, 4, 8 and $12 \mathrm{~h}$ after the start of culture with those of oocytes collected from large follicles 4 and $8 \mathrm{~h}$ after hCG injection and those of oocytes collected from oviductal ampulla 12 and $16 \mathrm{~h}$ after hCG injection. The distribution of active mitochondria in the ooplasm was also examined.

Experiment 3: To determine the period in which nucleosides affected the MMP of oocytes during $12 \mathrm{~h}$ of culture for in vitro maturation, OCCs were cultured in the absence or presence of nucleosides for the first $4 \mathrm{~h}$ or the latter $8 \mathrm{~h}$ of IVM. Following culture, the nuclear maturation of the oocytes was examined. The MMP of mature oocytes (as determined by the presence of the first polar body) was also observed.

Experiment 4: To determine whether adenosine detrimentally affects the MMP of the oocyte during the latter phase of in vitro maturation, OCCs were exposed to $10 \mu \mathrm{g} / \mathrm{ml}$ adenosine or a mixture of $10 \mu \mathrm{g} / \mathrm{ml}$ guanosine, $10 \mu \mathrm{g} / \mathrm{ml}$ cytidine and $10 \mu \mathrm{g} / \mathrm{ml}$ uridine for the latter $8 \mathrm{~h}$ of a 12-h culture period. Following culture, nuclear maturation and the MMP of mature oocytes were observed.

Experiment 5: The effect on the developmental competence of oocytes exposured to adenosine during the latter $8 \mathrm{~h}$ of IVM was examined. OCCs were cultured in nucleoside-free IVM medium for $4 \mathrm{~h}$ and then cultured in the absence or presence of $10 \mu \mathrm{g} / \mathrm{ml}$ adenosine for $8 \mathrm{~h}$. Mature oocytes were denuded in M2 medium containing $0.1 \%$ hyaluronidase and then activated in $\mathrm{Ca}^{2+}$-free $\mathrm{CZB}$ containing $10 \mathrm{mM} \mathrm{SrCl}{ }_{2}$ and $5 \mu \mathrm{g} / \mathrm{ml}$ cytochalasin B for $6 \mathrm{~h}$ [23]. The oocytes were then washed several times and cultured in kSOMaa medium [24] supplemented with $1 \mathrm{mg} / \mathrm{ml}$ BSA for $96 \mathrm{~h}$. After culture, all embryos that developed to the blastocyst stage were examined to determine the number of cells they contained by fluorescence staining with Hoechst 33342.

\section{Statistical analysis}

The data from four replicated experiments were statistically analyzed by one-way ANOVA and Duncan's multiple range test using the StatView software (Abacus Concepts, Berkeley, CA, USA). All data were expressed as means \pm SEM. A value of $\mathrm{P}<0.05$ was considered to be statistically significant. 
Table 1. Meiotic maturation of oocytes following culture in the absence and presence of nucleosides or following ovulation

\begin{tabular}{ccclcc}
\hline Treatments* & $\begin{array}{c}\text { No. of oocytes } \\
\text { examined }\end{array}$ & $\begin{array}{c}\text { No. (\%) of oocytes } \\
\text { induced into GVBD }\end{array}$ & \multicolumn{2}{c}{$\begin{array}{c}\text { No. (\%) of oocytes } \\
\text { developed to MII }\end{array}$} \\
\hline A+ & 92 & 80 & $(87.6 \pm 4.4)^{\mathrm{b}}$ & 74 & $(82.0 \pm 4.9)$ \\
$\mathrm{A}-$ & 100 & 99 & $(98.8 \pm 1.2)^{\mathrm{c}}$ & 84 & $(86.0 \pm 3.8)$ \\
$\mathrm{B}+$ & 84 & 84 & $(100)$ & 76 & $(90.5 \pm 4.1)$ \\
$\mathrm{B}-$ & 99 & 98 & $(98.9 \pm 1.1)$ & 83 & $(82.2 \pm 8.5)$ \\
Ovulated & 61 & 61 & $(100)$ & $59 \quad(96.7 \pm 3.3)$ \\
\hline
\end{tabular}

Data are presented as means \pm SEM from 4 replicates. $*$ OCCs collected $0 \mathrm{~h}(\mathrm{~A})$ or $4 \mathrm{~h}(\mathrm{~B})$ after hCG injection were cultured in the absence (-) or presence (+) of nucleosides for 16 and $12 \mathrm{~h}$, respectively. Ovulated oocytes were collected $16 \mathrm{~h}$ after hCG injection. ${ }^{a}$ Percentage of the number of oocytes examined.

\section{Results}

Effect of nucleosides on nuclear maturation and MMP of oocytes (Exp. 1)

Table 1 shows that there was a reduction in the incidence of oocytes induced into GVBD when oocytes were cultured with nucleosides for $16 \mathrm{~h}$ (87.6\%) compared with the other four groups (98.8-100\%). The percentage of oocytes developed to the MII stage did not differ between the groups examined (82.0-96.7\%). However, the MMP of the mature oocytes cultured in the presence of nucleosides was significantly lower than that of oocytes matured in the absence of nucleosides and that of oocytes matured in vivo (Fig. 1).

Comparison of meiotic progression and the MMPs of oocytes cultured in the presence of nucleosides for various durations with those of oocytes matured in vivo (Exp. 2)

The incidence of mature oocytes was not significantly different $(\mathrm{P}>0.05)$ when oocytes cultured in the presence of nucleosides were compared with those collected from follicles at the same time after hCG injection (Table 2). An increase in MMP of oocytes was observed between oocytes collected 8 and $12 \mathrm{~h}$ after hCG injection, whereas no significant increase in MMP was observed in oocytes cultured in the presence of nucleosides. MMP was lower in oocytes matured in vitro than in those matured in vivo at 12 and 16 $\mathrm{h}$ after hCG injection (Fig. 2). There was no significant difference in the distribution pattern of active mitochondria in ooplasm between oocytes matured in vivo and those matured in vitro for several hours after hCG injection (Fig. 3, Table 3).

\section{Period when nucleosides affect the MMP of oocytes during} meiotic maturation (Exp.3)

The incidences of oocytes induced into GVBD and that developed to the MII stage did not differ among the conditions examined (Table 4). There were no significant differences in the MMPs of mature oocytes cultured in any of the conditions examined, except for those exposed to nucleosides for the latter $8 \mathrm{~h}$ of IVM, which showed a lower MMP than observed under the other conditions (Fig. 4).

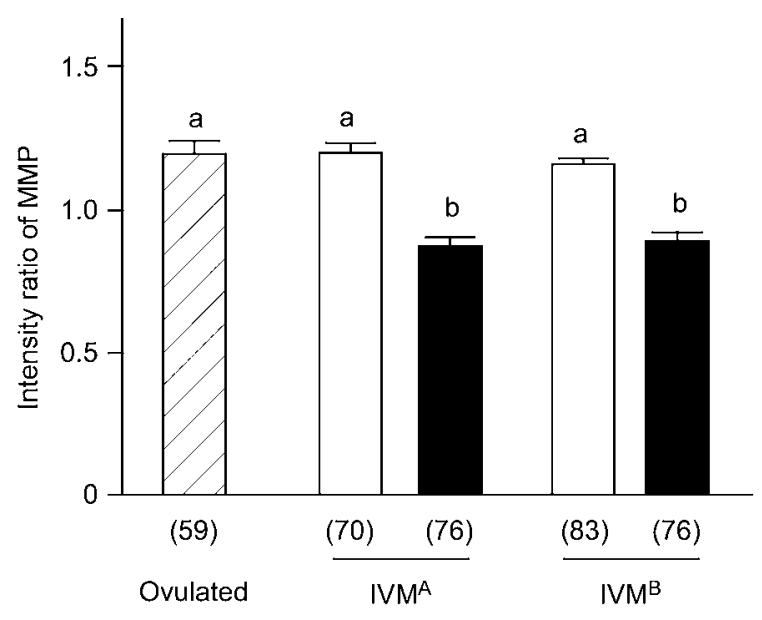

Fig. 1. MMPs of the oocytes ovulated (diagonal bar) or cultured in the absence (white bar) or presence (black bar) of nucleosides. OCCs collected $0 \mathrm{~h}$ (A) or $4 \mathrm{~h}$ (B) after hCG injection were cultured for 16 and $12 \mathrm{~h}$, respectively. Ovulated oocytes were collected $16 \mathrm{~h}$ after hCG injection. Values with different superscripts are significantly different $(\mathrm{P}<0.05)$.

Effect of adenosine on nuclear maturation and MMP of oocytes during meiotic maturation (Exp. 4)

The incidences of oocytes induced into GVBD and that developed to the MII stage did not differ among the conditions examined (Table 5). As shown in Fig. 5, the MMPs of mature oocytes cultured in the presence of adenosine or nucleosides did not differ, but their potentials were lower compared with oocytes matured in vivo or cultured in the presence of a mixture ribonucleosides without adenosine (guanosine, cytidine and uridine).

Developmental competence of oocytes matured with adenosine and then chemically actiavated (Exp. 5)

When oocytes were matured in the presence of adenosine and then chemically activated, the incidence of pronuclear formation was significantly decreased $(\mathrm{P}<0.05)$ compared with oocytes matured in vivo or those cultured in the absence of adenosine (Table 6). There were no significant differences in the incidences of cleavage and blastocyst formation, regardless of the presence of adenosine during the later $8 \mathrm{~h}$ of IVM. However, there were fewer 
Table 2. Comparison of the meiotic progression of oocytes cultured in the presence of nucleosides (in vitro) with that of oocytes collected at corresponding times (in vivo)

\begin{tabular}{|c|c|c|c|c|c|c|c|}
\hline \multirow{2}{*}{$\begin{array}{c}\text { Culture } \\
\text { period (h) }\end{array}$} & \multirow{2}{*}{$\begin{array}{l}\text { Origin of } \\
\text { oocytes }\end{array}$} & \multirow{2}{*}{$\begin{array}{l}\text { No. of oocytes } \\
\text { examined }\end{array}$} & \multicolumn{5}{|c|}{ No. $(\%)^{b}$ of oocytes at: } \\
\hline & & & $\mathrm{GV}$ & ProMI & MI & AI \& TI & MII \\
\hline 0 & In vivo & 71 & $12(16.2 \pm 5.4)$ & $59(83.8 \pm 5.4)$ & 0 & 0 & 0 \\
\hline \multirow[t]{2}{*}{4} & In vitro & 84 & $15(18.0 \pm 9.3)$ & $31(38.8 \pm 10.4)$ & $38(43.2 \pm 13.5)$ & 0 & 0 \\
\hline & In vivo & 76 & $7 \quad(9.5 \pm 5.8)$ & $26(32.1 \pm 8.7)$ & $43(58.4 \pm 7.4)$ & 0 & 0 \\
\hline \multirow[t]{2}{*}{8} & In vitro & 83 & $2 \quad(2.3 \pm 2.3)$ & $2 \quad(3.6 \pm 3.6)$ & $15(23.5 \pm 16.8)$ & 0 & $64(70.6 \pm 20.2)$ \\
\hline & In vivo & 70 & $3 \quad(4.5 \pm 1.5)$ & $5 \quad(7.7 \pm 4.6)$ & $15(20.9 \pm 8.4)$ & 0 & $47(66.9 \pm 10.7)$ \\
\hline \multirow[t]{2}{*}{12} & In vitro & 84 & 0 & 0 & $6 \quad(7.2 \pm 3.2)$ & $2(2.4 \pm 1.4)$ & $76(90.5 \pm 4.1)$ \\
\hline & In vivo & 61 & 0 & 0 & $2 \quad(3.3 \pm 3.3)$ & 0 & $59(96.7 \pm 3.3)$ \\
\hline
\end{tabular}

Data are presented as means \pm SEM from 4 replicates. ${ }^{\text {a }}$ OCCs collected $4 \mathrm{~h}$ after hCG injection were cultured in the presence of nucleosides for various periods. In vivo oocytes were collected at corresponding times. ${ }^{\mathrm{b}}$ Percentage of the number of oocytes examined.

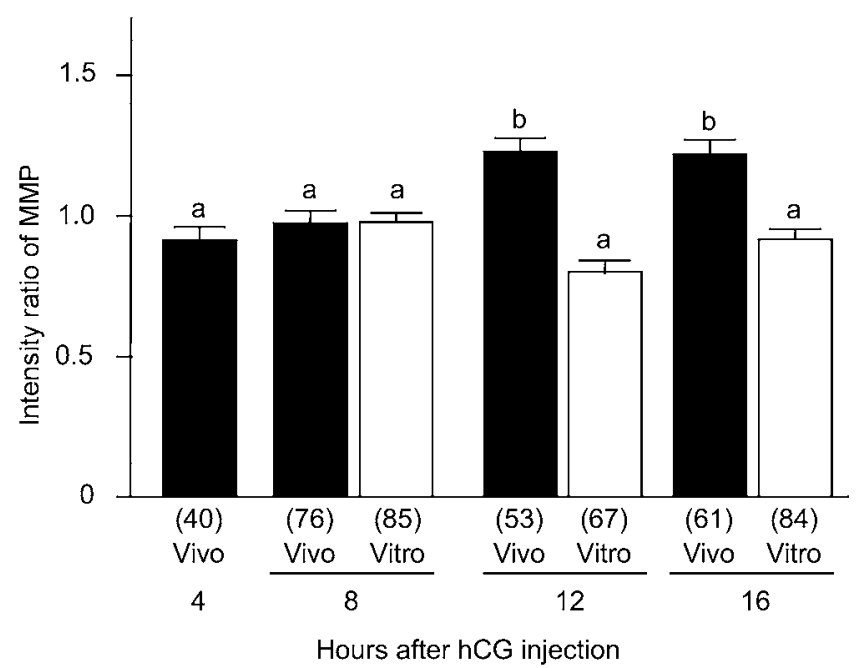

Fig. 2. MMPs of oocytes at various times during meiotic maturation in vivo (black bars) or during in vitro culture with nucleosides (white bars). Values with different superscripts are significantly different $(\mathrm{P}<0.05)$.

number of oocytes at each stage in vitro than in the oocytes matured in vivo.

\section{Discussion}

In the present study, we found that the presence of adenosine during the latter $8 \mathrm{~h}$ of IVM culture significantly affected the MMP of mature oocytes at the end of culture. To our knowledge, this is the first paper to show a detrimental effect of heterogeneous nucleosides, especially adenosine, on oocyte MMP. Although adenosine has no effect on the activation of glycolysis or oxidation of pyruvate, it is known to have at least a partial inhibitory effect on hormone-induced maturation that suppresses activation of the pentose phosphate pathway [25]. In the present study, a lower MMP was observed for mature oocytes, even when the OCCs were collected before hCG injection. The MMP of oocytes collected from oviducts $12 \mathrm{~h}$ after hCG injection was significantly higher than that of oocytes from follicles $8 \mathrm{~h}$ after hCG injection. At $12 \mathrm{~h}$ after hCG injection ( $8 \mathrm{~h}$ of culture), a majority of the oocytes were at metaphase II, whereas MMP was still at the basal level $8 \mathrm{~h}$ after hCG injection (4 h of culture) when the majority of the oocytes were at the metaphase I. The MMP of mature oocytes cultured in the presence of nucleosides remained constant during the whole culture period. Therefore, these results indicate that the MMP of oocytes assessed with JC- 1 increases in the final phase of maturation and that this increase is prevented in the presence of adenosine. Furthermore, the presence of nucleosides during the first $4 \mathrm{~h}$ of culture did not affect the MMP of mature oocytes, and the MMPs of the oocytes were comparable whether the oocytes were ovulated mature oocytes or cultured in the absence of nucleosides. Thus, the increase in mitochondrial activity is prevented only when nucleosides are present during the latter $8 \mathrm{~h}$ of culture.

Our final experiment showed that, out of all the nucleosides examined, only adenosine inhibited the increase in MMP, decreased the competence of oocytes to form pronuclei and consequently decreased development to the first cleavage. Since mitochondria are the powerhouses of cells and play a crucial role in $\mathrm{Ca}^{2+}$ signaling that mediates oocyte activation and development [26], their activity should reflect the developmental competence of oocytes and embryos [27], whereas high-polarized mitochondria are required for penetration and cortical granule exocytosis [28]. Irregular mitochondrial function has been suggested to interfere with the order chromosome segregation [7]. Adenosine has been shown to cause depolarization of the mitochondrial inner membrane by opening mitochondrial ATP-sensitive potassium channels in some types of somatic cell [29, 30]. The concentration of adenosine in follicular fluid has been shown to decrease from 0.35 $0.70 \mathrm{mM}$ to $0.26-0.53 \mathrm{mM}$ in eCG-primed mice and eCG-primed mice $5 \mathrm{~h}$ after hCG injection, respectively [11]. In the present study, we added an extremely low concentration of adenosine (10 $\mu \mathrm{g} / \mathrm{ml}=37.4 \mu \mathrm{M}$ ) to the maturation media. Although the concentration of adenosine surrounding the ovulating oocyte is unknown, under the current in vitro conditions, the mouse oocytes during the latter half of maturation were more susceptible to adenosine, and consequently a low MMP could decrease the fertilization and early developmental abilities of the oocytes.

Previous reports have shown that nucleosides, such as adenosine and guanosine, maintain meiotic arrest in OCCs [15, 16, 25]. Adenosine has been known to maintain the level of intracellular cAMP in GV oocytes for meiotic arrest, to inhibit de novo purine synthesis 
Table 3. Comparison of the distributions of mitochondria in oocytes at the stages of GV, MI to TI and MII at various times of culture with those of oocytes collected at corresponding times

\begin{tabular}{|c|c|c|c|c|c|c|c|c|c|c|c|c|c|c|c|}
\hline \multirow{3}{*}{$\begin{array}{l}\text { Culture } \\
\text { period } \\
\text { (h) }\end{array}$} & \multirow{3}{*}{$\begin{array}{c}\text { Origin } \\
\text { of } \\
\text { oocytes }\end{array}$} & \multirow{3}{*}{$\begin{array}{c}\text { No. of } \\
\text { oocytes } \\
\text { examined }\end{array}$} & \multicolumn{13}{|c|}{ Percentage of oocytes with active mitochondria distributed to each criteria* } \\
\hline & & & \multicolumn{3}{|c|}{ GV stage $(\%)^{b}$} & \multicolumn{5}{|c|}{ Pro-MI to TI stages $(\%)^{b}$} & \multicolumn{5}{|c|}{ MII stage $(\%)^{b}$} \\
\hline & & & $\mathrm{d} \overline{\text { WO }}$ & $\mathrm{NM}$ & $\mathrm{PM}$ & WO & PM & SF & LF & $\mathrm{CF}$ & WO & $\overline{\mathrm{PM}}$ & SF & LF & $\mathrm{CF}$ \\
\hline $0 \mathrm{~h}$ & In vivo & 70 & $9.2 \pm 4.0$ & $3.6 \pm 2.2$ & $4.4 \pm 2.6$ & $20.2 \pm 5.1$ & $1.1 \pm 1.1$ & $24.4 \pm 8.9$ & $37.1 \pm 14.2$ & - & - & - & - & - & \\
\hline \multirow[t]{2}{*}{$4 \mathrm{~h}$} & In vitro & 77 & $7.7 \pm 4.4$ & $1.9 \pm 1.9$ & $8.7 \pm 7.4$ & - & $4.5 \pm 3.4$ & $41.3 \pm 4.0$ & $31.8 \pm 12.6$ & $4.1 \pm 2.9$ & - & - & - & - & - \\
\hline & In vivo & 71 & $9.6 \pm 7.4$ & $1.8 \pm 1.8$ & $3.1 \pm 3.1$ & $1.6 \pm 1.6$ & $7.8 \pm 7.8$ & $54.2 \pm 10.2$ & $21.9 \pm 9.0$ & - & - & - & - & - & - \\
\hline \multirow[t]{2}{*}{$8 \mathrm{~h}$} & In vitro & 90 & - & - & - & - & - & $1.1 \pm 1.1$ & $7.9 \pm 5.2$ & $3.8 \pm 3.8$ & $13.3 \pm 13.3$ & - & - & $60.8 \pm 9.1$ & $13.1 \pm 7.8$ \\
\hline & In vivo & 73 & $1.3 \pm 1.3$ & $1.7 \pm 1.7$ & - & - & - & $5.8 \pm 3.4$ & $5.3 \pm 5.3$ & $2.5 \pm 2.5$ & - & $2.9 \pm 1.7$ & - & $73.6 \pm 2.6$ & $6.9 \pm 5.0$ \\
\hline \multirow[t]{2}{*}{$12 \mathrm{~h}$} & In vitro & 84 & - & - & - & - & - & - & $2.9 \pm 2.9$ & $7.5 \pm 2.6$ & $7.5 \pm 2.6$ & - & - & $79.8 \pm 7.6$ & $2.3 \pm 2.3$ \\
\hline & In vivo & 61 & - & - & - & - & - & - & $3.3 \pm 3.3$ & - & $4.3 \pm 3.1$ & - & - & $91.3 \pm 6.3$ & $1.0 \pm 1.0$ \\
\hline
\end{tabular}

*Criteria for the distribution of active mitochondria: WO, whole ooplasm region; NM, near membrane region; PM, perinuclear and near membrane regions; SF, several foci; LF, a large focus; CF: a central focus (See Fig. 3). Data are presented as means \pm SEM from 4 replicates. ${ }^{\text {a }}$ OCCs collected $4 \mathrm{~h}$ after hCG injection were cultured in the presence of nucleosides for various periods. In vivo oocytes were collected at corresponding times. ${ }^{\mathrm{b}}$ Percentage of the number of oocytes examined.

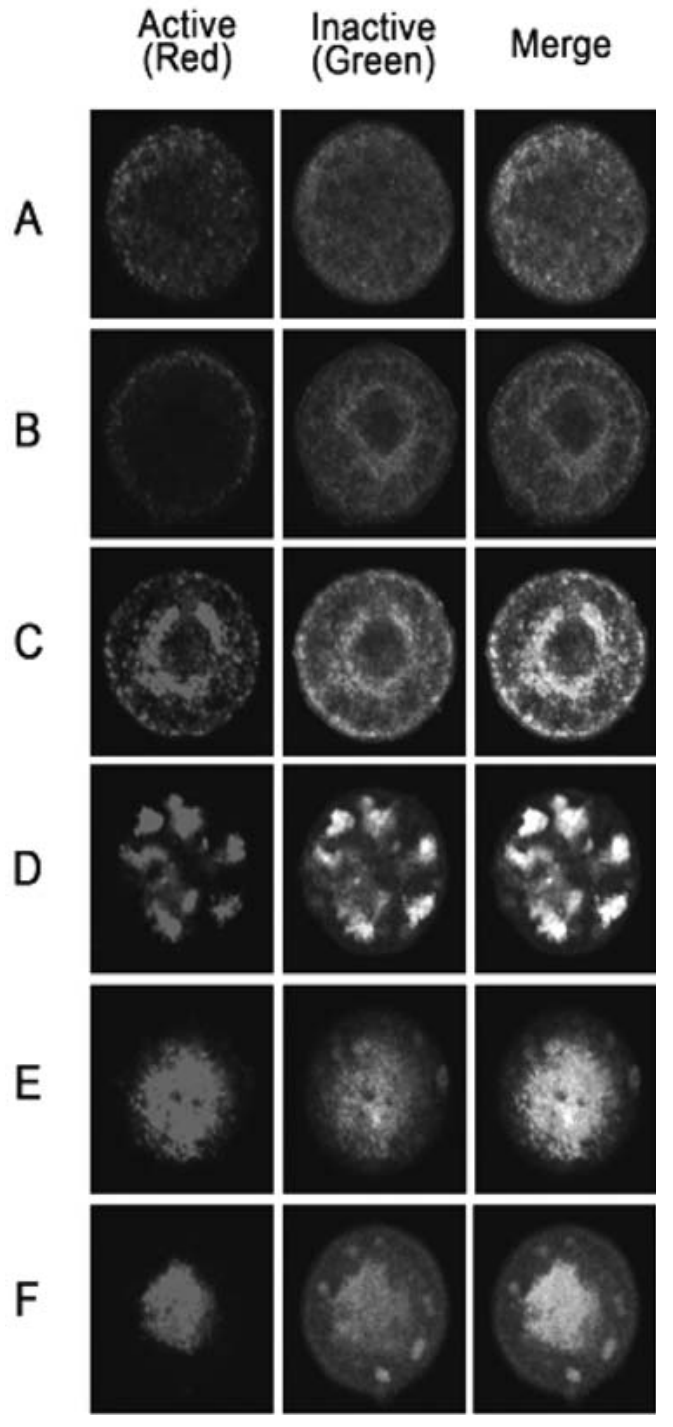

Fig. 3. Distribution patterns of JC-1 aggregated active mitochondria. Active mitochondria (red fluorescence) distributed throughout the whole ooplasm (WO; A), to the near membrane region (NM; $\mathrm{B})$, to the perinuclear and near membrane regions (PM; C), to several foci in the neutral region (SF; D), to a large focus at the central region (LF; E) and to a central focus (CF; F). and consequently to prevent meiotic resumption of oocytes [11, 12]. The uridine taken up by cumulus cells is transferred to the oocytes [13], and this blocks adenosine uptake by oocyte cumulus complexes [14]. In the present study, however, when OCCs were cultured in alpha-MEM with nucleosides, including both uridine and adenosine, during the whole period of in vitro maturation, the incidence of oocytes matured to the metaphase-II stage was not significantly different from that of oocytes subjected to IVM in nucleoside-free alpha-MEM medium, although fewer oocytes underwent GVBD. The oocytes used in the present study were collected from large antral follicles or the oviducts of mice following hormonal treatments, and following GVBD, a majority of the oocytes matured to further meiotic stages. Our results demonstrate that if OCCs are stimulated by gonadotropins, nucleosides do not drastically prevent meiotic progression. This is consistent with a previous report showing that adenosine and inhibitors of de novo purine synthesis have no effect on the completion of maturation [31].

Following binding to the receptors at the cell surface, adenosine acts through the adenylate cyclase pathway. The receptors have been known to be expressed in both oocytes [32] and cumulus cells [33]. Adenosine A1 and A3 receptors have been known to activate adenylate cyclase, and conversely, A2 receptors inhibit adenylate cyclase [34]. However, in the present study, the mechanism by which adenosine prevented the increase in oocyte MMP during in vitro maturation was not determined. Further studies are required to verify the mechanisms of the inhibitory effect of exogenous adenosine on oocyte MMP during in vitro maturation. In the present study, we observed that the distribution of active mitochondria assessed with JC-1, as well as the total MMP, dramatically changed during oocyte maturation in vivo and in vitro. Although the active MMPs of oocytes with mitochondria distributed throughout the whole ooplasm and to the near membrane region were much lower than the MMP of oocytes with mitochondria distributed to a large focus at the central region, we did not find any differences in the distribution of mitochondria between oocytes maturing in vivo and in vitro in the presence of adenosine. These observations show that adenosine affects MMP, but not the distribution of mitochondria.

Although mitochondrial membrane potential is known to be higher for in vivo-matured oocytes compared with oocytes matured 
Table 4. Meiotic maturation of oocytes cultured in the absence or presence of nucleosides during the first $4 \mathrm{~h}$ and/or latter $8 \mathrm{~h}$ of IVM

\begin{tabular}{|c|c|c|c|c|}
\hline \multicolumn{2}{|c|}{ Presence of nucleosides $^{\mathrm{a}}$} & \multirow{2}{*}{$\begin{array}{l}\text { No. of oocytes } \\
\text { examined }\end{array}$} & \multirow{2}{*}{$\begin{array}{l}\text { No. (\%) of oocytes } \\
\text { induced into GVBD }\end{array}$} & \multirow{2}{*}{$\begin{array}{l}\text { No. (\%) of oocytes } \\
\text { developed to MII }\end{array}$} \\
\hline First $4 \mathrm{~h}$ & Latter $8 \mathrm{~h}$ & & & \\
\hline- & - & 105 & $105(100)$ & $92(87.4 \pm 5.1)$ \\
\hline+ & - & 111 & 111 (100) & $103(93.7 \pm 2.6)$ \\
\hline- & + & 86 & 86 (100) & $81 \quad(94.1 \pm 3.0)$ \\
\hline \multicolumn{2}{|c|}{ Ovulated oocytes } & 61 & 61 (100) & $59(96.7 \pm 3.3)$ \\
\hline
\end{tabular}

Data are presented as means \pm SEM from 4 repricates. ${ }^{a}$ OCCs collected $4 \mathrm{~h}$ after hCG injection were cultured in the absence or presence of nucleosides for the first $4 \mathrm{~h}$ and/or latter $8 \mathrm{~h}$ of a total 12-h period. Ovulated oocytes were collected $16 \mathrm{~h}$ after hCG injection. ${ }^{\text {bPercent }}$ of the number of oocytes examined.

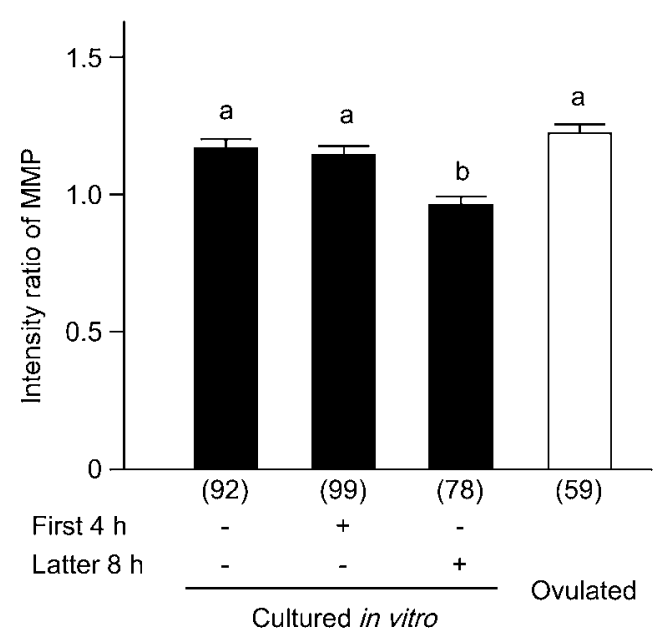

Fig. 4. MMPs of oocytes cultured with or without nucleosides for the first $4 \mathrm{~h}$ or the latter $8 \mathrm{~h}$ (black bars) and of oocytes matured in vivo (white bar). Values with different superscripts are significantly different $(\mathrm{P}<0.05)$.
Table 5. Meiotic maturation of oocytes cultured in the presence of nucleosides, adenosine or a mixture of guanosine, cytidine and uridine (GCU-combo) and of ovulated oocytes collected from oviducts

\begin{tabular}{lccc}
\hline Treatments $^{\mathrm{a}}$ & $\begin{array}{c}\text { No. of oocytes } \\
\text { examined }\end{array}$ & $\begin{array}{c}\text { No. (\%) of oocytes } \\
\text { induced into GVBD }\end{array}$ & $\begin{array}{c}\text { No. (\%) of oocytes } \\
\text { matured to MII }\end{array}$ \\
\hline Nucleosides & 86 & $86(100)$ & $81(94.1 \pm 3.0)$ \\
Adenosine & 84 & $84(100)$ & $83(98.9 \pm 1.1)$ \\
GCU-combo & 89 & $89(100)$ & $88(99.0 \pm 1.0)$ \\
Ovulated & 61 & $61(100)$ & $59(96.7 \pm 3.3)$ \\
\hline
\end{tabular}

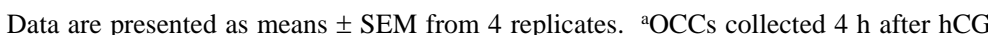
injection were cultured in the presence of nucleosides, adenosine or GCU-combo for the latter $8 \mathrm{~h}$ of a total 12-h period. Ovulated oocytes were collected $16 \mathrm{~h}$ after hCG injection. 'Percent of the number of oocytes examined. under $20 \% \mathrm{O}_{2}$ [35], the current study using alpha-MEM without adenosine did not show any differences in MMP between oocytes matured in vivo and in vitro. The changes in the distribution of active mitochondria observed in the present study during oocyte maturation were similar in oocytes collected in vivo and those cultured in vitro, and the distributional changes were similar to those previously reported $[8,9]$. Therefore, in regard to in vitro maturation of mouse oocytes, the evidence suggests that the culture conditions used in the present study are suitable. Sufficient developmental competence has been shown for oocytes matured in alpha-MEM without nucleosides in a previous study [36], although the presence of nucleosides has not been clear in some studies [37, 38 ] that have examined the developmental competence of mouse oocytes matured in alpha-MEM. The present results provide evidence of the advantages of using alpha-MEM without adenosine.

In conclusion, we have demonstrated that adenosine inhibits increase of the MMP of oocytes during the latter half of meiotic maturation. Maturation of oocytes in the presence of adenosine considerably decreases pronuclear formation and developmental competence, resulting in an inadequate MMP for oocyte maturation.

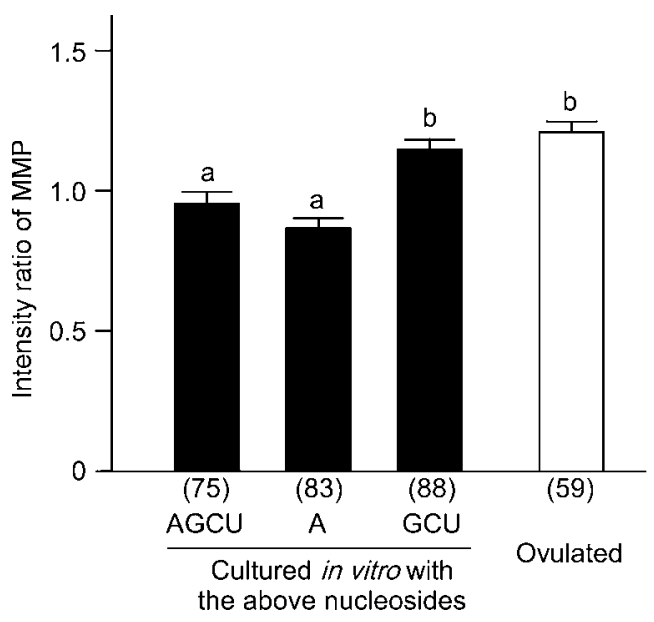

Fig. 5. MMPs of oocytes cultured with various combinations of nucleosides (A, adenosine; G, guanosine; C, cytidine; U, uridine) for the latter $8 \mathrm{~h}$ of IVM (black bars) and of oocytes matured in vivo (white bar). Values with different superscripts are significantly different $(\mathrm{P}<0.05)$. 
Table 6. In vitro development of oocytes ovulated or matured in the absence or presence of adenosine for the latter $8 \mathrm{~h}$ of a total 12 -h period following chemical activation

\begin{tabular}{lccccc}
\hline Treatments* & $\begin{array}{c}\text { No. of oocytes } \\
\text { stimulated }\end{array}$ & $\begin{array}{c}\text { No. (\%) of oocytes } \\
\text { that survived }\end{array}$ & $\begin{array}{c}\text { No. (\%) of oocytes } \\
\text { that formed PN }\end{array}$ & $\begin{array}{c}\text { No. (\%) of oocytes } \\
\text { that cleaved }\end{array}$ & $\begin{array}{c}\text { No. (\%) of oocytes } \\
\text { that formed blastocysts }\end{array}$ \\
\hline Adenosine-free & 85 & $84(99.0 \pm 1.0)$ & $64(71.0 \pm 12.4)^{\mathrm{a}}$ & $64(71.0 \pm 12.4)^{\mathrm{a}}$ & $33(34.7 \pm 10.5)^{\mathrm{a}}$ \\
Adenosine & 86 & $86(100)$ & $11(13.2 \pm 3.9)^{\mathrm{b}}$ & $9(10.3 \pm 1.8)^{\mathrm{b}}$ & 3 \\
Ovulated & 91 & $77(85.3 \pm 12.5)$ & $75(98.3 \pm 1.7)^{\mathrm{a}}$ & $74(96.0 \pm 2.4)^{\mathrm{a}}$ & $73(92.4 \pm 3.0)^{\mathrm{c}}$ \\
\hline
\end{tabular}

Data are presented as means \pm SEM from 4 replicates. * OCCs collected $4 \mathrm{~h}$ after hCG injection were cultured in the absence (adenosine-free) or presence of adenosine for the latter $8 \mathrm{~h}$ of a total 12-h period. Ovulated oocytes were collected $16 \mathrm{~h}$ after hCG injection. ${ }^{\mathrm{a}-\mathrm{c}}$ Values with different superscripts within the same row are significantly different $(\mathrm{P}<0.05)$.

\section{Acknowledgements}

The authors would like to thank Dr. N Satake (University of Queensland, Brisbane, Australia) for critically reading this report and offering suggestions. This work was funded by the RyobiTeien Foundation. The authors declare that there is no conflict of interest that would prejudice the impartiality of this scientific work.

\section{References}

1. Wassarman PM, Albertini DF. The Mammalian ovum. In: Knobil E, Neill JD (eds.), The Physiology of Reproduction, Vol. 1, New York: Raven Press; 1994: 79-122.

2. Tsafriri A, Motola S. Are steroids dispensable for meiotic resumption in mammals? Trends Endo Metabol 2007; 18: 321-327.

3. Bavister BD, Squirrell JM. Mitochondrial distribution and function in oocytes and early embryos. Hum Reprod 2000; 15 (Suppl 2) 189-198.

4. Van Blerkom J, Davis P, Alexander S. Differential mitochondrial distribution in human pronuclear embryos leads to disproportionate inheritance between blastomeres: relationship to microtubular organization, ATP content and competence. Hum Reprod 2000; 15: 2621-2633.

5. Meister A, Anderson ME. Glutathione. Annual Review Biochem 1983; 52: 11-60.

6. Quinn P, Wales R. The relationship between the ATP content of preimplantation mouse embryos and their development in vitro during culture. J Reprod Fertil 1973; 35: 301-309.

7. Beermann F, Hansmann I. Follicular maturation, luteinization and first meiotic division in oocytes after inhibiting mitochondrial function in mice with chloramphenicol. Mutation Res 1986; 160: 47-54.

8. Nishi Y, Takeshita T, Sato K, Araki T. Change of the mitochondrial distribution in mouse ooplasm during in vitro maturation. Nihon Ika Daigahu Zasshi 2003; 70: 408-415 (In Japanese).

9. Calarco PG. Polarization of mitochondria in the unfertilized mouse oocyte. Dev Genetics 1995; 16: 36-43.

10. Heller DT, Schultz RM. Ribonucleoside metabolism by mouse oocytes: metabolic cooperativity between the fully grown oocyte and cumulus cells. J Exp Zool 1980; 214: 355-364.

11. Downs SM, Daniel SA, Bornslaeger EA, Hoppe PC, Eppig JJ. Maintenance of meiotic arrest in mouse oocytes by purines: modulation of cAMP levels and cAMP phosphodiesterase activity. Gamete Res 1989; 23: 323-334.

12. Eppig JJ, Ward-Bailey PF, Coleman DL. Hypoxanthine and adenosine in murine ovarian follicular fluid: concentrations and activity in maintaining oocyte meiotic arrest. Biol Reprod 1985; 33: 1041-1049.

13. Salustri A, Siracusa G. Metabolic coupling, cumulus expansion and meiotic resumption in mouse cumuli oophori cultured in vitro in the presence of FSH or dcAMP, or stimulated in vivo by hCG. J Reprod Fertil 1983; 68: 335-341.

14. Downs SM. Uptake and metabolism of adenosine mediate a meiosis-arresting action on mouse oocytes. Mol Reprod Dev 1999; 53: 208-221.

15. Fagbohun CF, Downs SM. Maturation of the mouse oocyte-cumulus cell complex: stimulation by lectins. Biol Reprod 1990; 42: 413-423.

16. Downs SM, Daniel SA, Eppig JJ. Induction of maturation in cumulus cell-enclosed mouse oocytes by follicle-stimulating hormone and epidermal growth factor: evidence for a positive stimulus of somatic cell origin. J Exp Zool 1988; 245: 86-96.

17. Su YQ, Wigglesworth K, Pendola FL, O'Brien MJ, Eppig JJ. Mitogen-activated protein kinase activity in cumulus cells is essential for gonadotropin-induced oocyte meiotic resumption and cumulus expansion in the mouse. Endocrinology 2002; 143: 2221-2232.
18. Su YQ, Denegre JM, Wigglesworth K, Pendola FL, O’Brien MJ, Eppig JJ. Oocytedependent activation of mitogen-activated protein kinase (ERK1/2) in cumulus cells is required for the maturation of the mouse oocyte-cumulus cell complex. Dev Biol 2003; 263: 126-138.

19. Eppig JJ, Telfer EE. Isolation and culture of oocytes. Methods in Enzymology 1993; 225 $77-84$

20. Akiyama T, Nagata M, Aoki F. Inadequate histone deacetylation during oocyte meiosis causes aneuploidy and embryo death in mice. Proc Nat Acad Sci USA 2006; 103 7339-7344

21. Wilding M, Dale B, Marino M, di Matteo L, Alviggi C, Pisaturo ML, Lombardi L, De Placido G. Mitochondrial aggregation patterns and activity in human oocytes and preimplantation embryos. Human Reprod 2001; 16: 909-917.

22. Thouas GA, Trounson AO, Wolvetang EJ, Jones GM. Mitochondrial dysfunction in mouse oocytes results in preimplantation embryo arrest in vitro. Biol Reprod 2004; 71: 1936-1942.

23. Wakayama T, Perry AC, Zuccotti M, Johnson KR, Yanagimachi R. Full-term development of mice from enucleated oocytes injected with cumulus cell nuclei. Nature 1998; 394: 369-374.

24. Biggers JD, McGinnis LK, Raffin M. Amino acids and preimplantation development of the mouse in protein-free potassium simplex optimized medium. Biol Reprod 2000; 63: 281-293.

25. Downs SM. Adenosine blocks hormone-induced meiotic maturation by suppressing purine de novo synthesis. Mol Reprod Dev 2000; 56: 172-179.

26. Liu L, Hammar K, Smith PJ, Inoue S, Keefe DL. Mitochondrial modulation of calcium signaling at the initiation of development. Cell Calcium 2001; 30: 423-433.

27. Dumollard R, Duchen M, Carroll J. The role of mitochondrial function in the oocyte and embryo. Curr Topics Dev Biol 2007; 77: 21-49.

28. Van Blerkom J, Davis P, Van Blerkom J, Davis P. Mitochondrial signaling and fertilization. Mol Hum Reprod 2007; 13: 759-770.

29. Sato T, Sasaki N, O'Rourke B, Marban E. Adenosine primes the opening of mitochondrial ATP-sensitive potassium channels: a key step in ischemic preconditioning? Circulation 2000; 102: 800-805.

30. Minners J, Lacerda L, McCarthy J, Meiring JJ, Yellon DM, Sack MN. Ischemic and pharmacological preconditioning in Girardi cells and C2C12 myotubes induce mitochondrial uncoupling. Circulation Res 2001; 89: 787-792.

31. Downs SM, Chen J. Induction of meiotic maturation in mouse oocytes by adenosine analogs. Mol Reprod Dev 2006; 73: 1159-1168.

32. Fain JN, Malbon CC. Regulation of adenylate cyclase by adenosine. Mol Cell Biochem 1979; 25: 143-169.

33. Salustri A, Petrungaro S, Conti M, Siracusa G. Adenosine potentiates forskolininduced delay of meiotic resumption by mouse denuded oocytes: evidence for an oocyte surface site of adenosine action. Gamete Res 1988; 21: 157-168.

34. Billig H, Magnusson C. Gonadotropin-induced inhibition of oxygen consumption in rat oocyte-cumulus complexes: relief by adenosine. Biol Reprod 1985; 33: 890-898.

35. Preis KA, Seidel GE Jr, Gardner DK. Reduced oxygen concentration improves the developmental competence of mouse oocytes following in vitro maturation. Mol Reprod Dev 2007; 74: 893-903.

36. Ogura A, Suzuki O, Tanemura K, Mochida K, Kobayashi Y, Matsuda J. Development of normal mice from metaphase I oocytes fertilized with primary spermatocytes. Proc Nat Acad Sci USA 1998; 95: 5611-5615.

37. van de Sandt JJ, Schroeder AC, Eppig JJ. Culture media for mouse oocyte maturation affect subsequent embryonic development. Mol Reprod Devel 1990; 25: 164-171.

38. Marin BCL, Grondahl C, Murray A, Blume T, Su YQ, Eppig JJ. Meiosis-activating sterol promotes the metaphase I to metaphase II transition and preimplantation developmental competence of mouse oocytes maturing in vitro. Biol Reprod 2004; 70: 14581464 . 